\title{
Small Molecule NF-кB Inhibitors as Immune Potentiators for Enhancement of Vaccine Adjuvants
}

\author{
Brittany A. Moser', Yoseline Escalante-Buendia', Rachel C. Steinhardt', \\ Matthew G. Rosenberger ${ }^{1}$, Britteny J. Cassaidy', Nihesh Naorem ${ }^{1}$, Alfred C. Chon', \\ Minh H. Nguyen ${ }^{2}$, Ngoctran T. Tran ${ }^{2}$ and Aaron P. Esser-Kahn ${ }^{1 *}$
}

${ }^{1}$ Pritzker School of Molecular Engineering, The University of Chicago, Chicago, IL, United States, ${ }^{2}$ Department of Chemistry, Chemical Engineering and Materials Science, Biomedical Engineering, University of California, Irvine, Irvine, CA, United States

Adjuvants are added to vaccines to enhance the immune response and provide increased protection against disease. In the last decade, hundreds of synthetic immune adjuvants have been created, but many induce undesirable levels of proinflammatory cytokines including TNF- $\alpha$ and IL-6. Here we present small molecule NF-kB inhibitors that can be used in combination with an immune adjuvant to both decrease markers associated with poor tolerability and improve the protective response of vaccination. Additionally, we synthesize a library of honokiol derivatives identifying several promising candidates for use in vaccine formulations.

Keywords: adjuvants, vaccines, NF-кB, honokiol, capsaicin

\section{INTRODUCTION}

Vaccines remain one of the most effective ways of preventing disease. Despite their immense success in preventing diseases such as polio, tetanus, and small pox, diseases such as HIV and dengue present challenges that current clinical vaccine technologies cannot provide. To solve this problem, one strategy that has been explored is to include adjuvants, molecules that enhance the immune response (1). Although novel adjuvants generate higher quality immune responses that cannot be achieved with current approved adjuvants, to date, very few have been approved for use in human vaccines. This disconnect is due, in part, to the challenge of balancing the proinflammatory immune response with the protective, adaptive immune response (2-4). We recently reported that vaccines could be improved through the use of a peptide NF- $\kappa B$ inhibitor, SN50 in combination with an immune adjuvant (5). The addition of SN50 to adjuvanted vaccines led to increased safety of the adjuvant while enhancing protection against disease. Although this method proved both general across a wide range of adjuvants and effective against antigens of a variety of diseases, it still required a large amount of the peptide to enable optimal safety and protection. Scale-up of peptides present synthetic challenges and can result in expensive production costs, limiting their potential in a clinical setting $(6,7)$. Peptides might also induce an immune response against themselves leading to a potential for decreased enhancement in subsequent vaccinations. We chose to explore other small molecule NF- $\mathrm{kB}$ inhibitors as immune potentiators to overcome these challenges.

Here we demonstrate that select small molecule NF- $\mathrm{BB}$ inhibitors are effective at reducing adjuvant-induced inflammation while also increasing the adaptive humoral immune response. At the same time, we demonstrate that not all NF- $\mathrm{KB}$ inhibitors are effective immune potentiators. 
Of the molecules we tested, honokiol and capsaicin proved to be effective at both limiting inflammation and potentiating the protective response. Through knockout studies, we demonstrate that the increase in antigen specific antibodies is independent from the anti-inflammatory activity, which is congruent with our previous studies (5). To determine if these small molecules could be improved by chemical synthesis, we explored derivatives of honokiol and found several promising candidates for potential use in vaccines.

\section{RESULTS AND DISCUSSION}

\section{Exploration of Small Molecule NF-кB Inhibitors in vitro}

To begin exploring alternative NF- $\kappa \mathrm{B}$ inhibitors, we examined the literature for promising candidates. Due to the strong correlation between NF- $\mathrm{KB}$ activation and sepsis $(8)$, cancer $(9,10)$ and autoimmune disorders (11), a large library of NF- $\kappa$ B inhibitors have been identified (12). Small molecule NF- $\kappa$ B inhibitors often do not act on the NF- $\kappa \mathrm{B}$ subunits themselves, but rather inhibit particular proteins in the NF- $\kappa$ B pathway, upstream of NF$\mathrm{kB}$ translocation to the nucleus (see Supplementary Table S1). We first wanted to analyze the potential of a variety small molecule NF- $\mathrm{B}$ inhibitors to inhibit inflammation in vitro in combination with lipopolysaccharide (LPS), a TLR4 agonist. We chose several common commercially available NF- $\kappa \mathrm{B}$ inhibitors and tested them in RAW macrophages. We chose to examine: Cardamonin $(40 \mu \mathrm{M})$, Caffeic acid phenethyl ester (CAPE) $(100 \mu \mathrm{M})$, Withaferin A (WA) $(400 \mathrm{nM})$, Resveratrol $(10 \mu \mathrm{M})$, Salicin (100 nM), 5Z-7-Oxozeaenol (5-z-O) (5 $\mu \mathrm{M})$, Parthenolide $(20 \mu \mathrm{M})$, Honokiol $(20 \mu \mathrm{M})$, Capsaicin $(200 \mu \mathrm{M})$, PDK1/Akt/Flt dual pathway inhibitor (PDK1) $(1 \mu \mathrm{M})$, and GYY 4137 (GYY) $(200 \mu \mathrm{M})$. To determine if immune potentiation was specific to NF- $\kappa \mathrm{B}$ or general to all anti-inflammatory molecules, we included the most common FDA approved anti-inflammatory drugs, acetaminophen $(10 \mathrm{mM})$ and ibuprofen $(800 \mu \mathrm{M})(13$, 14). We treated RAW macrophages with inhibitors and LPS and assayed the supernatant for IL-6 secretion (Figure 1A). CAPE, WA, 5-Z-O, honokiol and capsaicin demonstrated the greatest reduction in IL-6 levels.

\section{Exploration of Small Molecule NF-кB Inhibitors in vivo}

We next wanted to examine how these inhibitors would alter safety and protection in vivo. To test this in vivo, we chose three of the small molecule inhibitors that were the most effective at inhibiting IL-6 expression in vitro, capsaicin, honokiol and withaferin A (WA) and ran them alongside acetaminophen and ibuprofen. We chose to vaccinate mice using CpG, a TLR9 agonist. For our in vivo vaccination, we used ovalbumin (OVA) as a model antigen to examine the changes in humoral response. We vaccinated mice with $100 \mu \mathrm{g}$ OVA, $50 \mu \mathrm{g} \mathrm{CpG}$, and inhibitor (800 $\mu \mathrm{g}$ ibuprofen, $2 \mathrm{mg}$ acetaminophen, $400 \mu \mathrm{g}$ honokiol, $20 \mu \mathrm{g}$ capsaicin or $600 \mu \mathrm{g}$ WA). Due to the difficulty in solubility of the inhibitors, all vaccines were formulated in Addavax, a squalene-based oil-in-water nano-emulsion, to enable effective vaccine suspensions. To enable comparison between groups PBS and $\mathrm{CpG}$ controls were also formulated in Addavax. We chose to analyze systemic levels of TNF- $\alpha$ and IL- 6 because high levels of these cytokines are pyrogenic and have been correlated with undesirable vaccine-related side effects (15-17). We previously determined that CpG-induced TNF- $\alpha$ and IL- 6 peak at $1 \mathrm{~h}$ postvaccination (5). Mice vaccinated with $\mathrm{CpG}$ demonstrated high levels of TNF- $\alpha$ (1067 pg/mL) (Figure 1B). Addition of an NF$\kappa \mathrm{B}$ inhibitor decreased the level of TNF- $\alpha$. Ibuprofen decreased to the mean level of TNF- $\alpha$ to $738 \mathrm{pg} / \mathrm{mL}$ (1.4 fold), acetaminophen $584 \mathrm{pg} / \mathrm{mL}$ (1.8 fold), honokiol $464 \mathrm{pg} / \mathrm{mL}$ (2.3 fold), capsaicin $38 \mathrm{pg} / \mathrm{mL}$ (28 fold, equivalent to background levels), and WA $580 \mathrm{pg} / \mathrm{mL}$ (1.8 fold). The systemic levels of IL-6 were also high with $\mathrm{CpG}$ vaccination $(941 \mathrm{pg} / \mathrm{mL})$. The groups that included an NF- $\kappa$ B inhibitor did not always decrease the level of IL-6 (Figure 1C). Ibuprofen, acetaminophen and WA did not alter the cytokine profile statistically significantly compared to $\mathrm{CpG}$ alone. Ibuprofen (1001 pg/mL) increased the level of IL-6 by 1.06 fold. Acetaminophen $(866 \mathrm{pg} / \mathrm{mL})$ decreased the level by 1.08 fold. WA increased the level of IL-6 to $967 \mathrm{pg} / \mathrm{mL}$ (1.02 fold increase). However, honokiol and capsaicin dramatically reduced the systemic levels of IL- 6 to $206 \mathrm{pg} / \mathrm{mL}$ (3.5 fold) and $47 \mathrm{pg} / \mathrm{mL}$ (20 fold), respectively.

To broadly establish how the addition of these inhibitors impacts the antibody levels, we chose to analyze the total Ig $(\mathrm{G}+\mathrm{A}+\mathrm{M})$ produced after 21 days (18). On day 21, we analyzed the anti-OVA antibody levels (Figure 1D). CpG was 1.6 fold (2312 U/mL) higher than PBS (1365 U/mL). Ibuprofen (708 $\mathrm{U} / \mathrm{mL})$ and acetaminophen $(955 \mathrm{U} / \mathrm{mL})$ were 3.2 and 2.4 fold lower that $\mathrm{CpG}$ alone. $\mathrm{CpG}+$ honokiol $(12286 \mathrm{U} / \mathrm{mL})$ was 5.3 fold more than $\mathrm{CpG}$ alone. $\mathrm{CpG}+$ capsaicin $(8413 \mathrm{U} / \mathrm{mL})$ was 3.6 fold higher than $\mathrm{CpG}$ alone. $\mathrm{CpG}+\mathrm{WA}(3459 \mathrm{U} / \mathrm{mL})$ was 1.5 fold higher than $\mathrm{CpG}$ alone.

These results demonstrate that honokiol and capsaicin are capable of both mitigating the systemic proinflammatory cytokines, TNF- $\alpha$ and IL-6, while also increasing the adaptive humoral response. WA demonstrated a decrease of systemic TNF- $\alpha$ while maintaining a similar antibody level as $\mathrm{CpG}$ alone. We were unable to formulate vaccines using CAPE and 5-z-O due to solubility issues; however, we believe they are worth exploring in future studies using alternative formulations.

\section{Dose-Dependence of Capsaicin and Honokiol}

Of the candidates, Capsaicin and honokiol demonstrated exceptional promise in these studies so we examined them further. To better understand how these molecules are altering the immune response over time, we vaccinated mice as described above and analyzed a larger variety of cytokines at various timepoints. We analyzed 13 cytokines: IL- $1 \alpha$, IL-1 $\beta$, IL-6, IL-10, IL-12p70, IL-17A, IL-23, IL-27, MCP-1, IFN- $\beta$, IFN- $\gamma$, TNF$\alpha$, and GM-CSF. Of these, only six cytokines demonstrated detectable levels in our assay: TNF- $\alpha$, IL-6, IL-10, IL-1 $\alpha$, MCP1 , and IFN- $\gamma$ (Figures 2A-F). Consistent with our previous findings (5), CpG induced TNF- $\alpha$ and IL-6 expression peaked 


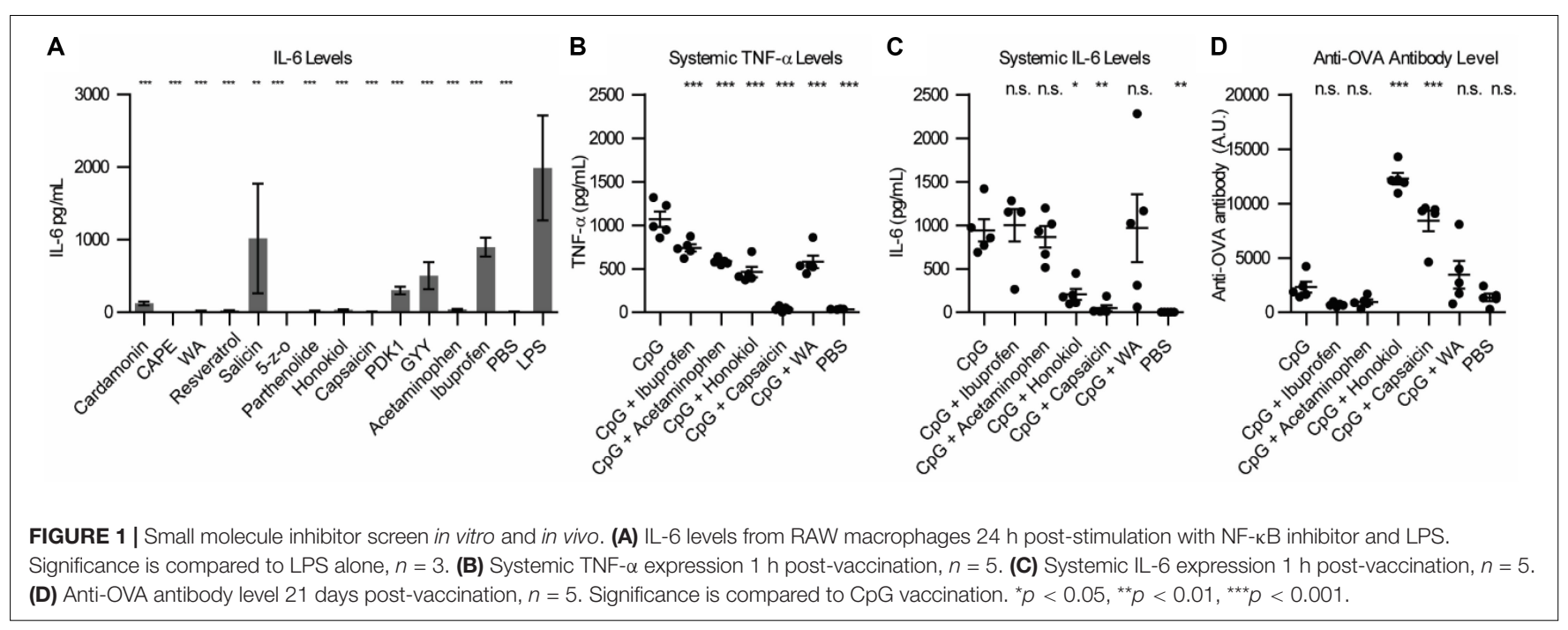

at $1 \mathrm{~h}$. Interestingly, $\mathrm{CpG}$ combined with either capsaicin or honokiol had increased IFN- $\gamma$ levels at $24 \mathrm{~h}$ compared to CpG alone (8 fold and 9 fold, respectively) and slightly elevated MCP1 levels (2.5 and 2 fold, respectively), demonstrating that both capsaicin and honokiol are acting to potentiate the immune response and are not simply suppressing immune activation. We next wanted to understand how changing the dose would alter innate and adaptive humoral immune responses. For honokiol, we tested a concentration 2 -fold higher $(800 \mu \mathrm{g})$ and 2 -fold lower $(200 \mu \mathrm{g})$ than the original dose $(400 \mu \mathrm{g})$. Mice vaccinated with our original dose of capsaicin $(20 \mu \mathrm{g})$ appeared lethargic for $30 \mathrm{~min}$ post-injection, therefore we wanted to examine if we could lower the dose, but maintain adequate anti-inflammatory activity and antibody-boosting potential. We chose to test a dose 4 -fold lower $(5 \mu \mathrm{g})$ and 20 -fold lower $(1 \mu \mathrm{g})$ than the original dose $(20 \mu \mathrm{g})$. Unfortunately, mice vaccinated with all doses of capsaicin appeared lethargic post-injection, however, mice vaccinated with the lowest dose of capsaicin $(1 \mu \mathrm{g})$ only appeared lethargic for ten minutes. All doses of honokiol demonstrated a significant decrease in TNF- $\alpha$ expression compared to $\mathrm{CpG}$ alone, however, there was no significant difference between the different doses (Figure 2G). Capsaicin decreased TNF- $\alpha$ levels significantly across all doses compared to $\mathrm{CpG}$ alone. Capsaicin doses of 5 and $20 \mu \mathrm{g}$ decreased levels of TNF- $\alpha$ significantly more than $1 \mu \mathrm{g}$ (Figure 2G). The level of IL-6 was only decreased with $400 \mu \mathrm{g}$ and $800 \mu \mathrm{g}$ honokiol and $20 \mu \mathrm{g}$ capsaicin (Figure 2H). Twenty-one days later, we analyzed differences in anti-OVA antibody level and found that all doses of honokiol increased levels of anti-OVA antibodies compared to $\mathrm{CpG}$ alone and the highest level was found with $400 \mu \mathrm{g}$ honokiol (Figure 2I). $1 \mu \mathrm{g}$ and $5 \mu \mathrm{g}$ of capsaicin did not change level of anti-OVA antibodies in the serum compared to $\mathrm{CpG}$ alone, however, $20 \mu \mathrm{g}$ significantly increased serum levels. These results indicate that honokiol can only limit TNF- $\alpha$ and IL- 6 to a certain extent at which higher doses do not provide additional decreases in these systemic inflammatory cytokines. Additionally, the highest dose of honokiol decreased the antibody level, indicating that there is an optimal dose at which this inhibitor can function as an immune potentiator. Capsaicin demonstrated a dosedependent response, where higher doses of capsaicin led to lower systemic TNF- $\alpha$ and IL-6 levels and higher antibody levels. This would point to a very promising candidate as an immune potentiator, however, these mice experienced other undesirable side effects (lethargy).

\section{Determining the TRPV1-Mediated Effects of Capsaicin}

The primary in vivo target for capsaicin is the transient receptor potential cation channel subfamily $\mathrm{V}$ member 1 (TRPV1). TRPV1 modulates the immune response in a variety of ways, and importantly, has been implicated in dampening systemic inflammation associated with sepsis (19-23). However, it has never been explored in a vaccine setting. To understand how activation of TRPV1 may be modulating the effects of the adjuvant, we compared the immediate inflammatory response of the vaccination in wild type mice (WT) and TRPV1 knockout mice. We vaccinated WT and TRPV1 KO mice with $100 \mu \mathrm{g}$ OVA and: $50 \mu \mathrm{g} \mathrm{CpG}, 50 \mu \mathrm{g} C p G+20 \mu \mathrm{g}$ capsaicin or PBS. We analyzed systemic levels of TNF- $\alpha$ and IL-6 $1 \mathrm{~h}$ after vaccination. We found that CpG induced high levels of TNF- $\alpha$ and IL6 in both WT and TRPV1 KO mice. Addition of capsaicin dramatically and significantly reduced both TNF- $\alpha$ levels and IL-6 levels in the WT mice (Figures 3A,B and Supplementary Figure S1). Although the mean was slightly lower for both TNF$\alpha$ and IL- 6 in the TRPV1 KO mice, these differences were not statistically significant. This demonstrated that TRPV1 activation is responsible for the capsaicin-induced decrease in systemic cytokine levels. As expected, the TRPV1 KO mice did not experience the lethargy experienced by the WT mice in response to capsaicin, indicating that activation of TRPV1 is responsible for this response. To examine if the increased antibody level was due to TRPV1 activation on day 21, we analyzed levels of antiOVA antibodies in the serum (Figure 3C and Supplementary Figure S1). Interestingly, we found that anti-OVA antibody levels were increased in groups with Capsaicin $+\mathrm{CpG}$ in both WT 


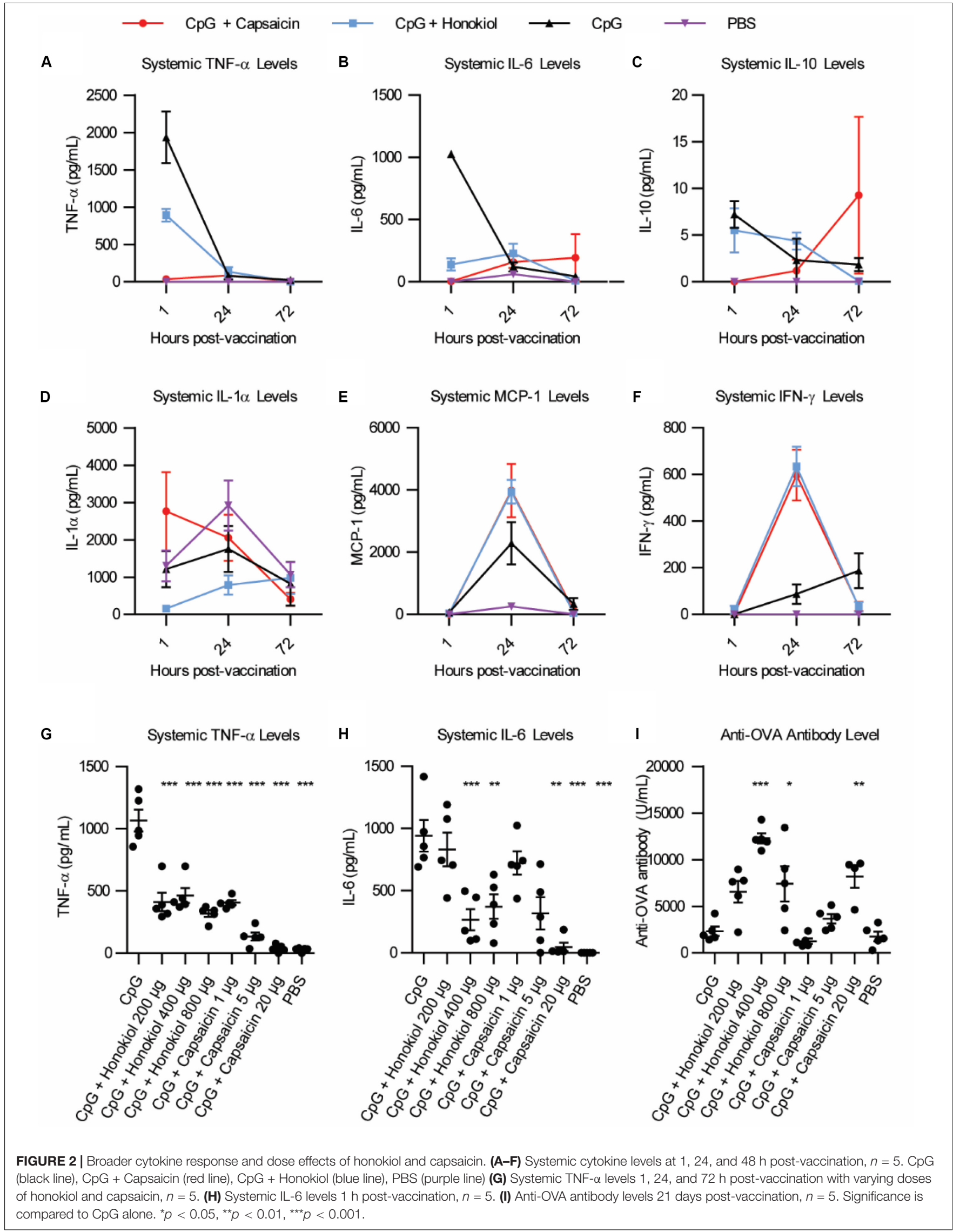


and $\mathrm{KO}$ mice. This implies that the antibody-boosting activity of capsaicin is separate from TRPV1-dependent decrease in inflammatory cytokines. This result demonstrates both that the decrease in inflammation is not responsible for the antibodyboosting activity of the NF- $\mathrm{B}$ inhibitor and also that the enhancement of the adaptive humoral response is independent of TRPV1 activation. These results, while not definitive, showed two separate, but correlated mechanisms for capsaicin that result in the reduction in cytokines and increase antibody levels. As such, capsaicin did not warrant further examination as a potential clinical immune potentiator. We will explore the mechanistic implications of this for immune potentiators more broadly in future publications.

\section{Synthesis of Honokiol Derivative Library}

With capsaicin possessing two parallel mechanisms and possessing well-established side effects (24), we wanted to explore honokiol for further development as a candidate. Oral intake of honokiol has been well studied in humans and has been established as safe with little to no side effects (25). However, it is subject to glucuronidation, leading to fast clearance (25). Additionally, vaccines for various diseases may require diverse potentiator activities. An important question for immune potentiators and honokiol was if standard SAR methods would yield alteration in potentiation activity. We wanted to investigate if compound libraries of promising immune potentiator candidates could be synthesized and provide alterations to activity. To further explore this idea, we synthesized a library of honokiol derivatives. Honokiol derivative libraries have been synthesized previously and examined for their effects on neuroprotection (26), antimicrobial agents (27) and anti-cancer (28) among others (29, 30). However, to date no such study has examined the effects of honokiol analogs on vaccines or a combination of anti-inflammatory activity and adaptive humoral immune response. Phenylphenols and biphenols were prepared using Pd-catalyzed Suzuki coupling using corresponding iodophenols and hydroxyphenylboronic acids as starting materials. These compounds were $\mathrm{O}$-allylated using allylBr. Resulting compounds were subjected to Claisen rearrangement using diethyl aluminum chloride to yield a variety of ring substitutions (Scheme 1 and Figure 4A).

We analyzed how the honokiol derivatives altered IL-6 production in RAW macrophages. We chose to analyze the
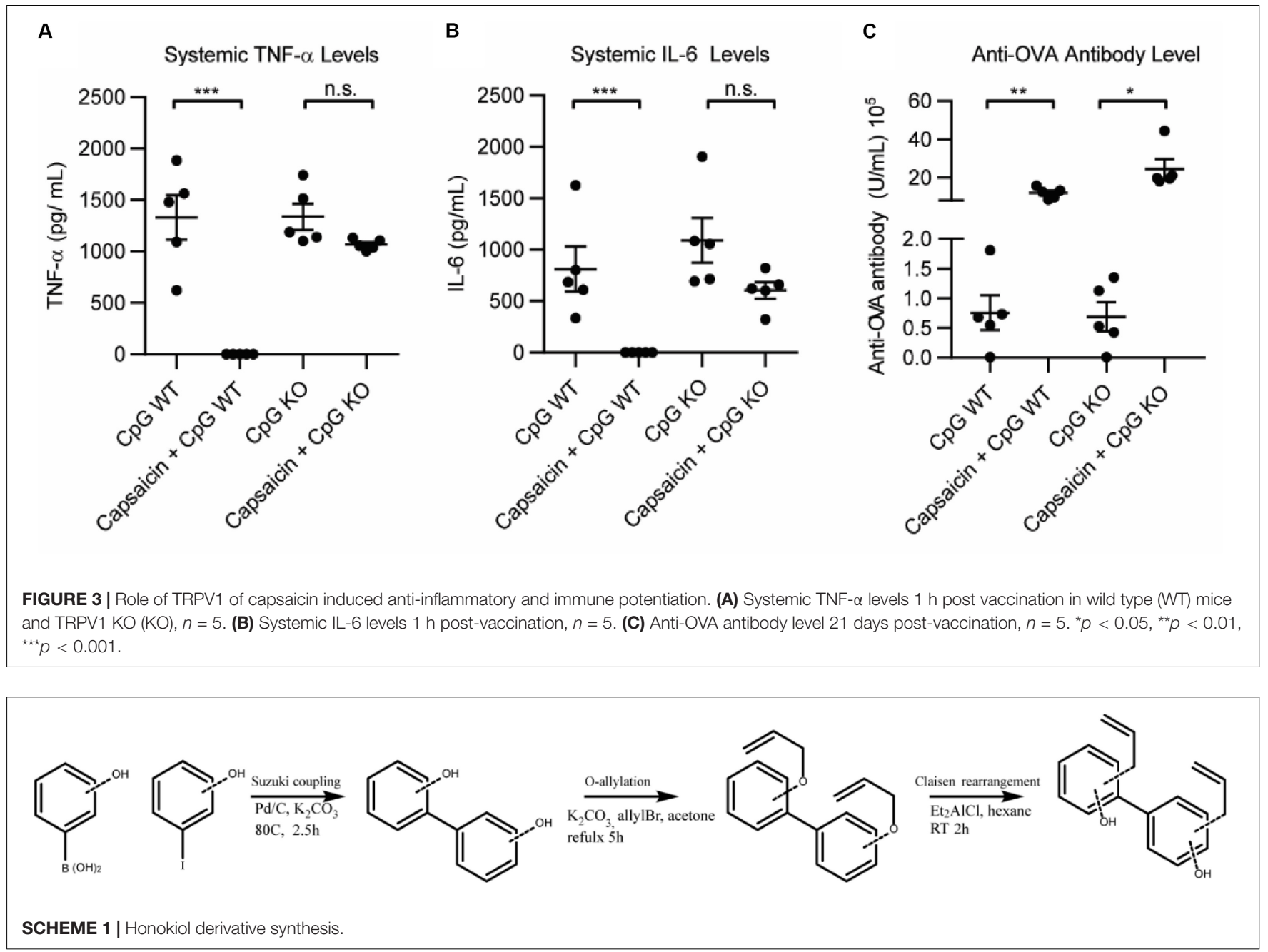


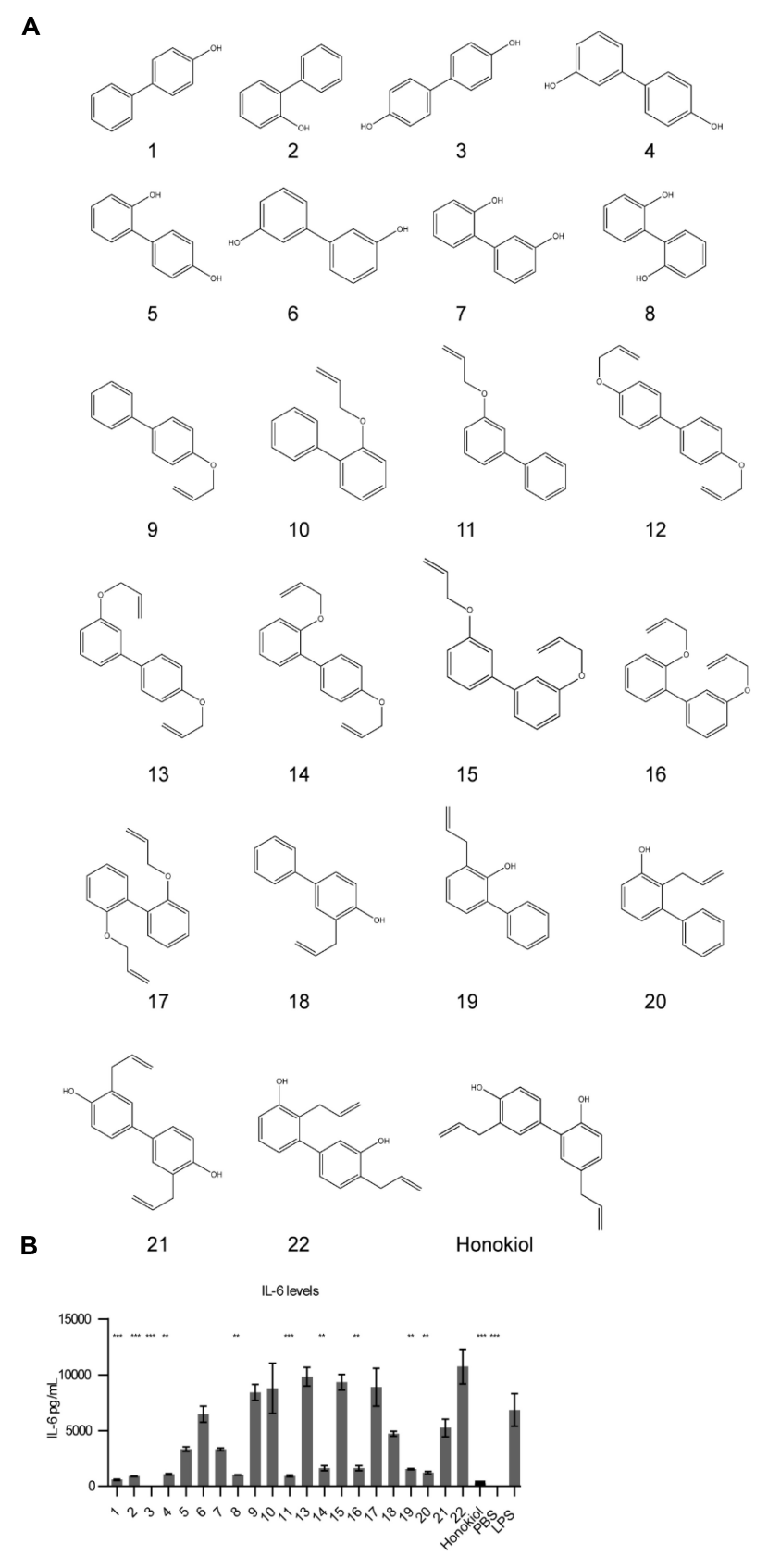

FIGURE 4 | Honokiol derivatives and their inhibitory activity on IL-6 expression. (A) Honokiol derivative library (B) IL-6 expression of RAW macrophages treated with honokiol derivatives and LPS, $n=3$. Significance is compared to LPS alone. ${ }^{* *} p<0.01,{ }^{* \star *} p<0.001$. hydroxybiphenyls and $O$-allylated derivatives in addition to the product from the Claisen rearrangement to understand how these functional groups play a role in the anti-inflammatory action or increase in adaptive immune response (Figure $4 \mathbf{B}$ and Supplementary Figures S2, S3). We treated RAW macrophages with honokiol derivatives and LPS and analyzed IL-6 expression. The addition of LPS alone without a honokiol derivative gave high levels of IL-6 expression ( $6848 \mathrm{pg} / \mathrm{mL})$. The addition of honokiol decreased IL-6 levels to $260 \mathrm{pg} / \mathrm{mL}$, a decrease of 26fold. Several derivatives including compounds: 1, 2, 3, 4, 8, and 11 demonstrated similar reductions in IL-6 expression in vitro making them promising candidates for in vivo analysis. As a small molecule, honokiol impacts multiple pathways aside from NF- $\kappa$ B such as: STAT3, EGFR, mTOR, and caspase-mediated common pathways (31). It is probable that alterations to the structure will impact which pathways are modulated, altering the downstream response. It is likely that different vaccine formulations will require potentiators with unique modulatory characteristics as well as pharmacokinetic/pharmacodynamic properties. Compounds lacking a free hydroxyl group (such as 11) are unable to form glucuronide conjugates, potentially extending the half-life. Here we demonstrated that compound libraries can be synthesized and screened in vitro for immune activity and that alterations to the structure change the downstream response. Such libraries could be used for improving rational design of future immune potentiators through machine learning. In future studies we will explore the effects of these inhibitors in vivo.

\section{CONCLUSION}

In summary, we present that select small molecule inhibitors of NF- $\kappa \mathrm{B}$ can decrease the inflammatory effects of adjuvanted vaccination - potentially enabling safer vaccination while also acting as immune potentiators and increasing the antibody level. We identified two such immune potentiators, honokiol and capsaicin that effectively decrease inflammation while increasing the adaptive humoral response. We additionally provide evidence that implies that the decrease in inflammation is separate from the increase in antibody response, potentially enabling distinct tunability of either response. This study also identifies that only select NF-кB inhibitors can be used as immune potentiators, this broadens the potential for further modulation of the immune response. We additionally synthesized and examined a library of honokiol derivatives and found that several honokiol derivatives are promising candidates for future testing in vivo. In the future, this information can be used in modern screening methods involving machine learning to identify better immune potentiators. The use of combining NF-kB inhibitors with vaccine adjuvants could find use in creating next-generation prophylactic vaccines and immunotherapy applications. In conclusion, we have demonstrated that using small molecule NF- $\kappa$ B inhibitors in combination with common immune adjuvants can decrease the production of pro-inflammatory cytokines TNF- $\alpha$ and IL- 6 while boosting antibody levels.

\section{MATERIALS AND METHODS}

\section{In vitro Assays RAW Macrophage Cytokine Analysis}

RAW 264.7 macrophages were passaged and plated in a cell culture treated 12 - well plate at $0.5 \times 10^{6}$ cells/well in $1 \mathrm{~mL}$ DMEM containing 10\% FBS. Cells were grown for 2 days. 
Media was exchanged for $1 \mathrm{~mL}$ DMEM containing 10\% HIFBS. Inhibitors were diluted in Addavax and then in PBS. Inhibitors were added at indicated concentrations and incubated for $45 \mathrm{~min}$. After $45 \mathrm{~min}$, LPS was added at $100 \mathrm{ng} / \mathrm{mL}$ and incubated at $37^{\circ} \mathrm{C}$ and $5 \% \mathrm{CO}_{2}$ for $24 \mathrm{~h}$. Cell supernatant was removed and analyzed using BD Cytometric Bead Array Mouse Inflammation Kit.

\section{Cell Viability Assay}

RAW macrophages were plated at $100 \mathrm{k}$ cells/well in 180 uL DMEM/10\% HIFBS. Inhibitors were diluted as described above and added at indicated concentrations and incubated for $45 \mathrm{~min}$. After $45 \mathrm{~min}$, LPS was added to a final concentration of $100 \mathrm{ng} / \mathrm{mL}$ and incubated at $37^{\circ} \mathrm{C}$ and $5 \% \mathrm{CO}_{2}$ for $24 \mathrm{~h}$. MTT reagent was made fresh at a concentration of $5 \mathrm{mg} / \mathrm{mL}$ in PBS and sterile filtered. $150 \mu \mathrm{L}$ cell supernatant was removed and $150 \mu \mathrm{L}$ PBS was added. $10 \mu \mathrm{L}$ MTT reagent was added to each well and incubated at $37^{\circ} \mathrm{C}$ and $5 \% \mathrm{CO}_{2}$ for $2 \mathrm{~h}$. $150 \mu \mathrm{L}$ supernatant was removed from each well and replaced with $150 \mu \mathrm{L}$ DMSO and incubated at $37^{\circ} \mathrm{C}$ and $5 \% \mathrm{CO}_{2}$ for $1 \mathrm{~h}$ or until purple crystals dissolved. Plate was analyzed using Multiskan FC plate reader (Thermo Fisher Scientific) and absorbance was measured at $450 \mathrm{~nm}$. Data was analyzed using Graphpad Prism.

\section{Flow Cytometry}

RAW macrophages $\left(2 \times 10^{6}\right)$ were plated in a 12 well plate in DMEM/10\% HIFBS. Inhibitors were diluted as described above and added at indicated concentrations and incubated for $45 \mathrm{~min}$. After $45 \mathrm{~min}$, LPS was added to a final concentration of $100 \mathrm{ng} / \mathrm{mL}$ and incubated at $37^{\circ} \mathrm{C}$ and $5 \% \mathrm{CO}_{2}$ for $24 \mathrm{~h}$. Cells were stained for CD86 using BD cytofix/cytoperm fixation/permeabilization solution kit according to manufacturer's protocol. Cells were analyzed using NovoCyte flow cytometer (ACEA Biosciences, Inc).

\section{In vivo Assays}

All animal procedures were performed under a protocol approved by the University of Chicago Institutional Animal Care and Use Committee (IACUC). 6-8 week-old C57/B6 female mice were purchased from Jackson Laboratory (JAX). 6-8 weekold C57/B6 female Trpv1 ${ }^{\text {tm1Ju }}$ mice were purchased from JAX for TRPV1 KO experiment. All compounds were tested for endotoxin prior to use. All vaccinations were administered intramuscularly in the hind leg. Blood was collected from the submandibular vein at time points indicated.

Antigens were purchased from Invitrogen (VacciGrade Ovalbumin). VacciGrade CpG ODN 1826 was purchased from Adipogen. AddaVax ${ }^{\mathrm{TM}}$ was purchased from Invivogen.

\section{Vaccination}

Mice were lightly anesthetized with isoflurane and injected intramuscularly in the hind leg with $50 \mu \mathrm{L}$ containing ovalbumin (100 $\mu \mathrm{g})$, adjuvant, inhibitor and PBS. Adjuvant doses: CpG, $50 \mu \mathrm{g}$. Inhibitor concentrations: Honokiol (400 $\mu \mathrm{g})$, Capsaicin (20 $\mu \mathrm{g})$, Withaferin A (600 $\mu \mathrm{g})$, acetaminophen (2 mg), ibuprofen $(800 \mu \mathrm{g})$. All vaccines contained $25 \mu \mathrm{L}$ AddaVax $^{\mathrm{TM}}$ to enhance solubility.

\section{Plasma Cytokine Analysis}

Blood was collected from mice at time points indicated in $0.2 \mathrm{~mL}$ heparin coated collection tubes (VWR Scientific). Serum was isolated via centrifugation $2000 \times g$ for $5 \mathrm{~min}$. Supernatant was collected and stored at $-80^{\circ} \mathrm{C}$ until use. Serum was analyzed using BD Cytometric Bead Array Mouse Inflammation cytokine kit or LEGENDplex ${ }^{\mathrm{TM}}$ Mouse Inflammation Panel (Biolegend) according to manufacturer's protocol.

\section{Antibody Quantification}

Mice were vaccinated with indicated formulations. Blood was collected at time points indicated in $0.2 \mathrm{~mL}$ heparin coated collection tubes (VWR Scientific) for plasma or uncoated tubes for serum. Plasma was isolated via centrifugation $(2000 \times g, 5 \mathrm{~min})$. Serum was isolated by allowing blood to clot for 15-30 min RT and centrifuging (2000 $\times g$ for $10 \mathrm{~min}$ ) at $4^{\circ} \mathrm{C}$. Serum was analyzed using a quantitative anti-ovalbumin total Ig's ELISA kit (Alpha Diagnostic International) according to the specified protocol. Data was analyzed using Graphpad Prism.

\section{Chemistry Conditions for Suzuki Coupling}

Hydroxyphenylboronic acid $(20 \mathrm{mmol})$ was dissolved in $100 \mathrm{~mL}$ water. Appropriate iodophenol $(10 \mathrm{mmol})$ and $\mathrm{K}_{2} \mathrm{CO}_{3}(40 \mathrm{mmol})$ was added followed by $\mathrm{Pd} / \mathrm{C}(2 \mathrm{~mol} \%)$. Solution heated to 80 $\mathrm{C}$ for $3 \mathrm{~h}$. Solution was acidified with $1 \mathrm{M} \mathrm{HCl}$ and extracted with EtOAc and washed with brine. Solvent evaporated in vacuo. Compound was purified by column chromatography.

\section{Conditions for O-Allylations}

Phenol (1 mmol) (Derivative 1-8) was dissolved in dry acetone $(5 \mathrm{~mL})$ and $\mathrm{K}_{2} \mathrm{CO}_{3}(2 \mathrm{mmol})$ added. AllylBr was added dropwise and refluxed. Reaction was monitored by TLC until completion (5-12 h). Reaction mixture was cooled and volatiles were removed in vacuo. $10 \% \mathrm{NaOH}$ was added to the mixture and extraction was performed using ethyl acetate, washed with brine and organic layers dried using $\mathrm{MgSO}_{4}$. Solvent was removed in vacuo affording an oily material that was purified by column chromatography to yield the O-allylated derivative.

\section{Conditions for Claisen Rearrangement}

O-allylated derivatives (9-17) (1 $\mathrm{mmol})$ were dissolved in dry hexane $(10 \mathrm{~mL})$. $\mathrm{Et}_{2} \mathrm{AlCl}$ in dry hexane $(4 \mathrm{~mL})$ was added dropwise under argon. Mixture was stirred at room temperature for $2 \mathrm{~h}$. The mixture was cooled on an ice bath and quenched using $2 \mathrm{M} \mathrm{HCl}(20 \mathrm{~mL})$. Extraction was performed with EtOAc, washed with brine and dried over MgSO4. Solvent was removed in vacuo affording an oily material that was purified by column chromatography to yield the C-allyl derivative.

\section{Statistics and Replicates}

Data is plotted and reported in the text as the mean \pm s.e.m. Sample size is as indicated in biological replicates in all in vivo and in vitro experiments. The sample sizes were chosen based on 
preliminary experiments or literature precedent indicating that the number would be sufficient to detect significant differences in mean values should they exist. $P$-values were calculated using a one-way ANOVA and Tukey post hoc test. All experiments have been repeated (sometimes with minor variations due to reagents and materials) and replication was successful.

\section{AUTHOR'S NOTE}

This manuscript has been released as a Pre-Print at ChemRxiv (32).

\section{DATA AVAILABILITY STATEMENT}

All datasets generated for this study are included in the article/Supplementary Material.

\section{ETHICS STATEMENT}

The animal study was reviewed and approved by the University of Chicago IACUC.

\section{REFERENCES}

1. Coffman RL, Sher A, Seder RA. Vaccine adjuvants: putting innate immunity to work. Immunity. (2010) 33:492-503. doi: 10.1016/j.immuni.2010.10.002

2. Audibert FM, Lise LD. Adjuvants: current status, clinical perspectives and future prospects. Trends Pharmacol Sci. (1993) 14:174-8. doi: 10.1016/01656147(93)90204-w

3. Bhardwaj N, Gnjatic S, Sawhney NB. TLR AGONISTS: are they good adjuvants? Cancer J. (2010) 16:382-91.

4. Tom JK, Albin TJ, Manna S, Moser BA, Steinhardt RC, Esser-Kahn AP. Applications of immunomodulatory immune synergies to adjuvant discovery and vaccine development. Trends Biotechnol. (2019) 37:373-88. doi: 10.1016/ j.tibtech.2018.10.004

5. Moser B, Steinhardt R, Escalante-Buendia Y, Boltz D, Barker K, Yoo S, et al. Increased vaccine tolerability and protection via NF-kB modulation. Sci. Adv. (2020) 6:eaaz8700. doi: 10.1126/sciadv.aaz8700

6. Lau JL, Dunn MK. Therapeutic peptides: historical perspectives, current development trends, and future directions. Bioorgan Med Chem. (2018) 26:2700-7. doi: 10.1016/j.bmc.2017.06.052

7. Otvos L, Wade JD. Current challenges in peptide-based drug discovery. Front Chem. (2014) 2:62. doi: 10.3389/fchem.2014.00062

8. Shimaoka M, Park EJ. Advances in understanding sepsis. Eur J Anaesthesiol. (2008) 25:146-53. doi: 10.1017/s0265021507003389

9. Dolcet X, Llobet D, Pallares J, Matias-Guiu X. NF-kB in development and progression of human cancer. Virchows Arch. (2005) 446:475-82. doi: 10.1007/ s00428-005-1264-9

10. Xia Y, Shen S, Verma IM. NF- $\kappa$ B, an active player in human cancers. Cancer Immunol Res. (2014) 2:823-30. doi: 10.1158/2326-6066.cir-140112

11. Bacher S, Schmitz ML. The NF-kB pathway as a potential target for autoimmune disease therapy. Curr Pharm Des. (2004) 10:2827-37. doi: 10. 2174/1381612043383584

12. Gilmore TD, Herscovitch M. Inhibitors of NF- $\kappa$ B signaling: 785 and counting. Oncogene. (2006) 25:6887-99. doi: 10.1038/sj.onc.1209982

\section{AUTHOR CONTRIBUTIONS}

$\mathrm{BM}$ and $\mathrm{AE}-\mathrm{K}$ conceived of and designed the project and experiments, and wrote the manuscript. BM, YE-B, RS, MR, $\mathrm{BC}, \mathrm{MN}$, and NT performed the experiments. BM synthesized the materials. BM, NN, and AC performed the compound characterization. All authors contributed to the article and approved the submitted version.

\section{FUNDING}

We would like to acknowledge support by the NIH (1U01Al124286-01 and 1DP2Al112194-01, GM099594). AE-K thanks the Pew Scholars Program and the Cottrell Scholars Program for generous support. BM thanks NSF-GRFP (DGE1321846). BC thanks NSF-GRFP (DGE-1746045). We would also like to thank NSF instrumentation grant CHE-1048528. This work was supported, in part, by a grant from the Alfred P. Sloan Foundation.

\section{SUPPLEMENTARY MATERIAL}

The Supplementary Material for this article can be found online at: https://www.frontiersin.org/articles/10.3389/fimmu. 2020.511513/full\#supplementary-material

13. Scheuren N, Bang $\mathrm{H}$, Münster $\mathrm{T}$, Brune $\mathrm{K}$, Pahl A. Modulation of transcription factor NF- $\mathrm{BB}$ by enantiomers of the nonsteroidal drug ibuprofen. Br J Pharmacol. (1998) 123:645-52. doi: 10.1038/sj.bjp.070 1652

14. Boulares AH, Giardina C, Inan MS, Khairallah EA, Cohen SD. Acetaminophen inhibits NF-kappaB activation by interfering with the oxidant signal in murine Hepa 1-6 cells. Toxicol Sci. (2000) 55:370-5. doi: 10.1093/toxsci/ 55.2.370

15. Christian LM, Porter K, Karlsson E, Schultz-Cherry S. Proinflammatory cytokine responses correspond with subjective side effects after influenza virus vaccination. Vaccine. (2015) 33:3360-6. doi: 10.1016/j.vaccine.2015.05.008

16. Simon WL, Salk HM, Ovsyannikova IG, Kennedy RB, Poland GA. Cytokine production associated with smallpox vaccine responses. Immunotherapy. (2014) 6:1097-112. doi: 10.2217/imt.14.72

17. Netea MG, Kullberg BJ, van der Meer JW. Circulating cytokines as mediators of fever. Clin Infect Dis. (2000) 31:S178-84.

18. Jung H, Kim D, Kang YY, Kim H, Lee JB, Mok H. CpG incorporated DNA microparticles for elevated immune stimulation for antigen presenting cells. RSC Adv. (2018) 8:6608-615. doi: 10.1039/C7RA13293J

19. Brito R, Sheth S, Mukherjea D, Rybak LP, Ramkumar V. TRPV1: a potential drug target for treating various diseases. Cells. (2014) 3:517-45. doi: 10.3390/ cells3020517

20. Wang Y, Wang DH. TRPV1 ablation aggravates inflammatory responses and organ damage during endotoxic shock. Clin Vaccine Immunol. (2013) 20:1008-15. doi: 10.1128/cvi.00674-12

21. Toledo-Mauriño JJ, Furuzawa-Carballeda J, Villeda-Ramírez MA, FonsecaCamarillo G, Meza-Guillen D, Barreto-Zúñiga $R$, et al. The transient receptor potential vanilloid 1 is associated with active inflammation in ulcerative colitis. Mediat Inflamm. (2018) 2018:6570371. doi: 10.1155/2018/657 0371

22. Bodkin JV, Fernandes ES. TRPV1 and SP: key elements for sepsis outcome? Br J Pharmacol. (2013) 170:1279-92. doi: 10.1111/bph.12056

23. Fernandes ES, Liang L, Smillie S-J, Kaiser F, Purcell R, Rivett DW, et al. TRPV1 deletion enhances local inflammation and accelerates the onset of 
systemic inflammatory response syndrome. J Immunol. (2012) 188:5741-51. doi: 10.4049/jimmunol.1102147

24. Winter JK, Bevan SA, Campbell EA. Capsaicin and pain mechanisms. Br J Anaesth. (1995) 75:157-68. doi: 10.1093/bja/75. 2.157

25. Sarrica A, Kirika N, Romeo M, Salmona M, Diomede L. Safety and toxicology of magnolol and honokiol. Planta Med. (2018). 84:1151-164. doi: 10.1055/a0642-1966

26. Tripathi S, Chan M-H, Chen C. An expedient synthesis of honokiol and its analogues as potential neuropreventive agents. Bioorgan Med Chem Lett. (2012) 22:216-21. doi: 10.1016/j.bmcl.2011.11.030

27. Kim Y-S, Lee J-Y, Park J, Hwang W, Lee J, Park D. Synthesis and microbiological evaluation of honokiol derivatives as new antimicrobial agents. Arch Pharm Res. (2010) 33:61-5. doi: 10.1007/s12272-0102225-7

28. Sánchez-Peris M, Murga J, Falomir E, Carda M, Marco JA. Synthesis of honokiol analogues and evaluation of their modulating action on VEGF protein secretion and telomerase-related gene expressions. Chem Biol Drug Des. (2017) 89:577-84. doi: 10.1111/cbdd.12880

29. Shen J-L, Man K-M, Huang P-H, Chen W-C, Chen D-C, Cheng Y-W, et al. Honokiol and magnolol as multifunctional antioxidative molecules for dermatologic disorders. Molecules. (2010) 15:6452-65. doi: 10.3390/ molecules 15096452

30. Lee Y-J, Lee YM, Lee C-K, Jung JK, Han SB, Hong JT. Therapeutic applications of compounds in the Magnolia family. Pharmacol
Ther. (2011) 130:157-76. doi: 10.1016/j.pharmthera.2011. 01.010

31. Rauf A, Patel S, Imran M, Maalik A, Arshad MU, Saeed F. Honokiol: An anticancer lignan. Biomed. Pharmacother. (2018) 107:555-62. doi: 10.1016/j. biopha.2018.08.054

32. Moser B, Escalante-Buendia Y, Steinhardt RC, Rosenberger M, Cassaidy B, Naorem N, et al. Small molecule NF-kB inhibitors as immune potentiators for enhancement of vaccine adjuvants. ChemRxiv [Preprint] (2019). doi: 10. 26434/chemrxiv.10043138.v1

Conflict of Interest: $\mathrm{BM}$ and $\mathrm{AE}-\mathrm{K}$ are inventors on a pending patent related to this work filed by the University of Chicago (no. PCT/US19/64888, filed 16 December 2019).

The remaining authors declare that the research was conducted in the absence of any commercial or financial relationships that could be construed as a potential conflict of interest.

Copyright (C) 2020 Moser, Escalante-Buendia, Steinhardt, Rosenberger, Cassaidy, Naorem, Chon, Nguyen, Tran and Esser-Kahn. This is an open-access article distributed under the terms of the Creative Commons Attribution License (CC BY). The use, distribution or reproduction in other forums is permitted, provided the original author(s) and the copyright owner(s) are credited and that the original publication in this journal is cited, in accordance with accepted academic practice. No use, distribution or reproduction is permitted which does not comply with these terms. 